\title{
Ethical risks of attenuating climate change through new energy systems: the case of a biofuel system
}

\author{
Sarah M. Jordaan* \\ University of Calgary, 2500 University Drive N.W., Calgary, Alberta T2N 1N4, Canada
}

\begin{abstract}
It has been estimated that a quarter of global energy could be consumed by transport, accounting for approximately $25 \%$ of total carbon dioxide emissions. This provides opportunity to reduce emissions through alternative fuels. As a result, biofuels have recently become the focus of many climate change policy discussions. However, those produced from agricultural crops are not greenhouse gas neutral and have the potential to transform many of the earth's natural landscapes into monocultures. This land transformation leads to ethical trade-offs that should be addressed before policy is put in place. These trade-offs will likely result in competing social institutions with different values. A scientific approach to assessing ethics is too reductionistic to achieve a fair outcome. Normative ethical theory is discussed as a means to deal with competing values in a just manner. The Wide Reflective Equilibrium (WRE) process should be used to achieve the fairest policy.
\end{abstract}

KEY WORDS: Energy systems - Transportation fuels · Biofuels · Climate change - Land transformation · Normative ethics

\section{INTRODUCTION}

It has been estimated that a quarter of global energy could be consumed by transport, accounting for approximately $25 \%$ of total carbon dioxide emissions, $80 \%$ of which can be attributed to road transport (UNEP 2007). This leaves significant room to reduce greenhouse gas emissions through alternative fuels. The policy option that has received the most attention by the US government and others has been a biofuel energy system. The US President's climate change plan proposed in the 2007 State of the Union speech can be used as an example. This plan was focused on fuel efficiency standards and alternative fuels, primarily ethanol (Harris 2007). Shifting from a fossil fuel to a biofuel system may result in substantial changes in how society impacts land (e.g. Worldwatch Institute 2006, Runge \& Senauer 2007). The potentially large amount of land required to support a large increase in biofuels may result in several externalities, or unintended sideeffects on people not directly involved with the development. The impacts of climate change will not be ad- dressed here, but rather ethical implications of policies that are believed to attenuate climate change.

The impacts of a biofuel policy and the ethical implications should be addressed as they may not be aligned with societal values. The salient point here is that ethical principles are needed for developing climate change policy in order to avoid such negative externalities. The argument will be made that switching to a biofuel energy system can result in the following ethical trade-offs related to land use

- Emissions may be reduced, but added crop production may affect the ability of the world's poor to feed themselves through increased demand.

- Environmentalists often value low-intensity crop production as it causes less environmental degradation and uses fewer fertilizers and fossil fuels. Higher intensity crop production would allow for greater output and less land transformation.

- Though climate change affects biodiversity, the land use associated with large-scale biofuel production has the potential to devastate ecosystems, especially in poor countries. 
- Finally, a shift to biofuels will result in rural economic development. This may have implications for the urban economy.

Currently there are no mechanisms to include ethical implications that arise from such trade-offs into climate change policies. Normative ethics are based on evaluative arguments that investigate competing values and externalities to determine what ought to occur in a given situation. In order to avoid potentially unethical impacts, normative ethical theory should be used in the development of such policies.

\section{BIOFUELS AND LAND TRANSFORMATION}

Biofuels have been defined as any type of liquid or gaseous fuel that can be produced from biomass and used as a substitute for fossil fuels (Giampietro et al. 1997). The focus of this paper is on transport biofuels, or those that can be used as a substitute for gasoline and diesel. These renewable transport fuels come in the form of ethanol and biodiesel. Though biofuels are reported to have less greenhouse gas emissions than fossil fuels (Farrell et al. 2006), potential impacts exist which may have ethical implications. Here, land use impacts are addressed. Though no studies were found that compare land transformation of fossil fuel production with biofuel production, a discussion of land use of different feedstocks for biofuels is still relevant.

When compared with gasoline and diesel, one must recognize that the land use associated with biofuels will likely be a permanent fixture on the landscape rather than short-term developments such as drilling and production of fossil fuels. Herein lies the significance of a biofuel system; potentially large tracts of land will be permanently converted for producing feedstocks. This section is meant to discuss the land transformation associated with different biofuels to provide background for the ethical discussion to come. The figure and table are meant to provide some background on the magnitude and variability in land impacts rather than provide definitive values for these feedstocks. There are a variety of feedstocks that can be used to produce these biofuels, each with different impacts to land. A range of these feedstocks and the yields of these feedstocks are shown in Fig. 1. In addition to these feedstocks, there are also waste-to-fuel forms of biofuels such as yellow grease for biodiesel. The focus of this paper will be on agricultural biofuels, but waste-tofuel will be briefly discussed later.
These values are subject to several uncertainties (Maclean 2006, Worldwatch Institute 2006). There will be variability in performance depending on soil quality, climate and other local environmental factors. Physical location of the production is an important factor for determining not only yield, but ecological impacts. Yields noted in Fig. 1 are for specific geographic locations; for example, sugarcane would not be relevant in Canada. The ecological impacts arising from these feedstocks will differ as there are different ecosystems and species being affected. As a result, the land will be valued differently by society. Yields are presented in terms of their geographic area in Table 1.

Several points should be highlighted that are significant for the ethical discussion to follow:

- Energy systems that attenuate climate change may have other significant impacts that are not immediately apparent.

- Investment in biofuels may result in negative impacts on nature and the people of developing countries. These externalities will be discussed in the following section.

- Some feedstocks have less impact per unit energy output and may thus be considered more environmentally effective. This, of course, also depends on the impacts on local ecosystems.

With the basic understanding of the implications of land transformation associated with biofuels, the ethical implications will be discussed.

\section{TRADE-OFFS INHERENT TO A BIOFUEL SYSTEM AND THE ETHICAL IMPLICATIONS}

An ideological distortion is 'an idea used by Marx and critical theorists to associate ideology with false

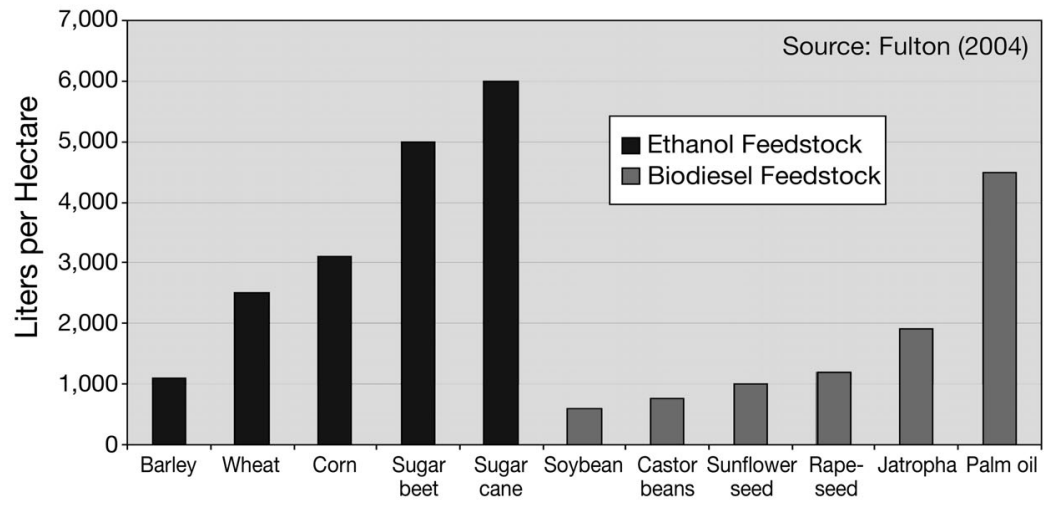

Fig. 1. Fulton (2004) estimates the yield associated with different feedstocks for transportation biofuels. Data are presented in terms of litres; it should be noted that $1 \mathrm{l}$ of biodiesel contains up to 1.6 times more energy than ethanol. There is still much uncertainty in these data; however, the results indicate the potential variability in land use associated with different feedstocks. This figure is taken with permission from Worldwatch Institute (2006) 
Table 1. Worldwatch Institute (2006) compiled studies with estimates on typical biofuel production ha ${ }^{-1}$ farmland by crop and region. Table used with permission from the Worldwatch Institute (2006)

\begin{tabular}{|c|c|c|c|c|c|}
\hline \multirow[t]{2}{*}{ Crop } & \multicolumn{5}{|c|}{ - Typical yield (l ha ${ }^{-1}$ cropland) } \\
\hline & $\begin{array}{l}\text { United } \\
\text { States }\end{array}$ & $\begin{array}{c}\text { European } \\
\text { Union }\end{array}$ & Brazil & India & Malaysia \\
\hline \multicolumn{6}{|l|}{ Ethanol source } \\
\hline Sugar cane & & & 6500 & 5300 & \\
\hline Sugar beet & & 5500 & & & \\
\hline Corn & 3100 & & & & \\
\hline Wheat & & 2500 & & & \\
\hline Barley & & 1100 & & & \\
\hline \multicolumn{6}{|l|}{ Biodiesel source } \\
\hline Palm oil & & & 5000 & & 6000 \\
\hline Rapeseed & & 1200 & & & \\
\hline Sunflower seed & & 1000 & & & \\
\hline Soybean & 500 & 700 & 400 & & \\
\hline Jatropha & & & & 700 & \\
\hline
\end{tabular}

consciousness, explaining why apparently irrational social and economic relations are accepted, even though not in the interest of those who accept them' (Harper \& Stein 2006, p. 305). Some believe that biofuels are a good environmental alternative for attenuating climate change. The belief that 'natural' systems are more environmentally benign has become an ideology of sorts. Here, ideology is meant in the broader sense to denote the normative justification of a political position regardless of legitimacy (Harper \& Stein 2006). As a result of this ideology, environmentalists are often proponents of 'natural' feedstocks to produce fuels and products. Ironically, life cycle assessments have often found that plastics and synthetics can use less energy and emit less greenhouse gases than more 'natural' feedstocks (Hendrickson et al. 2006). The danger is that unethical policies can be developed if we follow only the values of the group that upholds an ideological distortion.

This is not to argue that all biological feedstocks cannot be sustainable; it is to argue that society must carefully examine potential externalities to people and nature before developing policy. Four trade-offs are presented in order to discuss the externalities that may be created through biofuel policy. Each trade-off is stated as a normative question to encourage the reader to consider the ethical implications. These are listed as follows

- Should we develop biofuels if their production could be detrimental to the poor?

- Should we really be developing low intensity energy if it results in the destruction of more natural areas than high intensity energy?

- Should we only be focusing on the ecological aftereffects of climate change rather than the land impacts created by potential energy systems?
- Should we consider potential effects on rural and urban economies?

These are not only meant to challenge the pre-conceived notion that a biofuel is a good alternative for the future energy system, but also to bridge into a discussion of the ethical principles that should be used in the creation of climate change policy.

\section{Should we develop biofuels if their production could be detrimental to the poor?}

One topic that is currently being debated is the potential biofuel production to displace crops used for feeding the poor. Some claim this is a Malthusian argument and the ability of humans to increase yield has been underestimated (Peskett et al. 2007). The issue is not necessarily the competition for land, but also the increased price in a feedstock due to increased demand. For example, the impacts of President Bush's climate change policy have already been seen in Mexico. Runge \& Senauer (2007, p. 49) summarized the story:

In late 2006, the price of tortilla flour in Mexico, which gets $80 \%$ of its corn imports from the US doubled thanks partly to a rise in US corn prices from $\$ 2.80$ to $\$ 4.20$ a bushel over the previous several months.... With half of Mexico's 107 million people living in poverty and relying on tortillas as a main source of calories, the public outcry was fierce.

The claim that the argument is Malthusian is based only on land area needed for the development, not the impacts on supply and demand. Peskett et al. (2007) argue that some biofuels, such as jatropha, are not in competition with diets of the poor. Looking back to Table 1, we note that this is only one of many feedstocks used for biofuel and many of the others may very well impact the diets of the poor. Runge \& Senauer (2007) note the following: soybeans, rapeseeds, sunflower seeds, and most importantly cassava, a staple food in the poorest parts of sub-Saharan Africa, Asia, and Latin America.

Developed countries also consume more transportation fuel than developing countries (Chow et al. 2003); therefore, negative externalities created by fuel consumption may be displaced to developing nations that are harvesting biofuel feedstocks. Will these impacts be felt where the fuel is consumed or will it be experienced by other societies? It is potentially true that there is much land available for the added agricultural production associated with biofuels, as argued by biofuel 
proponents. Does this account for other land uses that may be competing for this land such as forestry and wilderness areas?

\section{Should we really be developing low intensity energy if it results in the destruction of more natural areas than high intensity energy?}

There is a large difference in the intensity of land use from different energy developments. Judgments about the environmental impacts associated with a development are made according to the intensity of development. Environmentalists often believe that low intensity development is more environmentally benign. An inherent trade-off exists between high and low intensity development. High intensity development has a higher yield, thus requiring less land than if developed with low intensity methods. The 'spared' land could be many things: untouched natural areas, other industrial development such as forestry, or urban development. In the case of biofuels, it is necessary to consider not only the amount of land needed to support such a system but also the yield levels of crop production (Berndes et al. 2003). For example, Victor \& Ausubel (2000) indicate that smarter agricultural techniques could be employed to increase future yield, thus freeing land for other uses. They suggest that if farmers increase yield by $2 \%$ a year in the US, 400 million ha of land could be spared from agricultural development.

This concept certainly applies if we compare transportation biofuels to fossil fuels. Based on the heating values of the fuels, it would take all 66 million ha of Alberta approximately $210 \mathrm{yr}$ to produce the same amount of energy contained in the oil sands from corn ethanol. This land area is roughly 5 times greater than the area that could be affected by the oil sands development. This conservative estimate is based only on the remaining established reserves of bitumen. I also assumed that the land could continuously produce this energy without becoming degraded. This does not mean that oil sands are more environmentally benign - they are arguably the highest greenhouse gas-emitting fuel currently being extracted for use in road transportation. However, the trade-offs between the two should be understood. The comparison could easily apply to high intensity versus low intensity biofuel crops as well.

\section{Should we only be focusing on the ecological after- effects of climate change rather than the land impacts created by potential energy systems?}

The ecological focus thus far has been on the impacts of changing climate; however, we should also consider potential land use impacts of new energy systems. It may very well be true that by 2050 climate change may drive between 18 and $35 \%$ of terrestrial species to extinction (Thomas et al. 2004), but what ecosystems will be affected by new energy systems? Climate impacts to terrestrial ecosystems may be diminished through shifting to biofuels, but the same ecosystems may be at risk of becoming agricultural developments for biofuels. It is important to understand ecological risks from climate change, but it is equally important to understand risks caused by climate change policy. Vitousek et al. (1997, p. 494) state 'the use of land to yield goods and services represents the most substantial human alteration of the Earth system.' Land transformation causes declines in biodiversity through 3 primary ways: loss and fragmentation of habitats; degradation of soil and water; and overexploitation of native species (Pimm \& Raven 2000). If biofuels are the primary focus of climate change policy, the reduction in greenhouse gas emissions may not save more species and ecosystems than what is lost through the land transformed for biofuel production.

Impacts may not be apparent as they may be displaced to other regions and countries. As shown in Table 1, production of feedstocks for biofuels occurs in a wide variety of geographic areas. Policy makers should understand where these biofuels come from and the local impacts to both ecosystems and economies. For example, Friends of the Earth reported in 2005 oil-palm plantations for biofuel could be responsible for $87 \%$ of deforestation between 1985 and 2000 in Malaysia (Buckland 2005). This is not to say investment in Malaysia should be stopped; this is where values of those involved become important. Lastly, there has been a debate as to whether or not biofuels are actually less greenhouse gas intensive. The answer to this has been 'yes' generally (Farrell et al. 2006), but the degree to which greenhouse gases are attenuated depends on the feedstock and processing (Mathews 2007).

\section{Should we consider potential effects on rural and urban economies?}

If a biofuel energy system emerged, economic development could potentially shift to the rural economy. Ugarte et al. (2006) estimate in the USA alone if 60 billion gallons (230 billion l) of ethanol and 1.6 billion gallons (6.1 billion l) of biodiesel were produced per year, 2.4 million jobs would be created, most of which would occur in the nation's rural economies. This would require more land for housing those that fill the new job placements. Farm incomes were estimated to achieve a $\$ 210$ billion (US) increase over the 2007 to 
2030 period. If farm incomes grow this much, will the urban economy be affected? The development of biofuels could boost rural economies and provide economic opportunity to use marginal lands in developing countries (Braun 2007). Both of these aspects could provide benefits, but it is unclear if there will be real winners and losers in this situation. First, uncertainty exists in the estimates for economic gains - higher production levels may affect feed requirements and may thus offset higher prices of grains for farms (Forge 2007). In addition, the international market will certainly determine the feedstock price. If incentives are put in place to increase ethanol, farmers will shift their crop production to ethanol feedstocks. The increase in supply would undoubtedly decrease the price of the feedstock and decrease supply of other crops. What implications are there for other agricultural products? Will rural economic development create migration from urban to rural economies or shift in agricultural crop production? Are there ethical implications here? Do we understand enough about the potential winners and losers in rural and urban environments?

\section{A PARADIGM FOR CLIMATE CHANGE POLICY DEVELOPMENT}

As indicated by the Buenos Aires Declaration on the Ethical Dimensions of Climate Change (Pennsylvania Consortium for Interdisciplinary Environmental Policy 2004), unless the ethical dimensions are considered when developing climate change policy, the international community may choose responses that are ethically unsupportable or unjust. As a result, government policy ought to consider ethical consequences of new energy systems. The biofuel case shows that ethical analyses are needed to determine whether national policy is based on ethically justifiable criteria. For biofuels, ethical implications discussed arise from impacts other than greenhouse gas emissions, namely land transformation. There is a need to develop a more complete set of policy-relevant indicators that better represent the impacts and trade-offs of new energy systems such as biofuels (Farrell et al. 2006). Once these are established, a fair playing field for assessing trade-offs can be developed. Science cannot account for how people value the trade-offs that are created through such a transition. The results should be deciphered through a new lens, a lens that pulls together science and humanities in unprecedented ways to create policy that best reflects society's values (Narasimhan 2007).

I argue that climate change policies should be developed based on normative arguments, evaluative arguments about how things ought to be, as suggested by Harper \& Stein (2006). As stated by Howe (1990, p. 123), 'normative ethics provides guidelines for deciding what makes right act right.' Arguments supporting biofuels are often based on purely descriptive arguments, that is, statements which are empirical and based on fact. The studies assumed that greenhouse gas reduction was the only environmental consequence. This is a reductionist approach to investigating the impacts associated with energy systems that is common to purely scientific approaches (Harper \& Stein 2006). The next question is: How can we ensure we are including all of the significant ethical issues?

We can capture where the ethical trade-offs lie by incorporating human values (e.g. wilderness values) and needs (e.g. food) into climate change policy. I argue that Rawl's (2001) process of Wide Reflective Equilibrium (WRE) should be used in order to identify ideological distortions and create the most ethical policies for attenuating climate change. This is a process Harper \& Stein (2006) suggest as the basis of planning theory in today's society. The notion of reflective equilibrium is 'a coherentist method of explanation and justification used in ethical theory, social and political philosophy, philosophy of science, philosophy of mind and epistemology' (Nielsen 1996, p. 13). Political positions must be justified to other citizens on the grounds of beliefs and political values. All views should be included, from scientific to valueladen. The WRE process is used to critique, develop, and reform public institutions, and seek coherence in relevant knowledge and information available to use (Harper \& Stein 2006). Harper \& Stein (2006, p. 147) suggest a dialogue-based approach. Here, 'an equilibrium is sought by working back and forth, revising the judgments, the normative theory, and the background theories ${ }^{1}$ until an equilibrium is reached (i.e. the comparisons no longer resulted in changes to any of the elements).' This would involve an in depth investigation of potential ethical implications of new policy, incorporating the views of many experts and stakeholders. As explained by Daniels (1979), we must not settle for the best judgments based on a preexisting set of principles; this would be a narrow equilibrium. We must instead develop philosophical arguments which bring out strengths and weaknesses of competing sets of principles. In the case of biofuels, this would require biofuel proponents to understand the ethical implications associated with agricultural feedstocks. A WRE process can be used to identify potential ideological distortions (Stein \& Harper 2005), for example, that all renewable energies are environ-

\footnotetext{
${ }^{1}$ Daniels (1979) identifies several background theories such as: general social theory, the theory of moral development, and the theory of the role of morality in society
} 
mentally benign. Such a process encourages policymakers to consider externalities caused by policy and determine which policy alternative is the fairest to those affected. Better indicators, such as those that describe land use impacts, are needed to assess the implications of climate change policy. These should be based on aspects of the environment that society values. This would require the process of scientific investigation to occur alongside the WRE process. Once better indicators are developed through investigating relevant societal values, the relevant externalities can be investigated and we can determine what policy ought to be developed.

Before concluding, one last question should be addressed: Do all types of biofuels give rise to these unethical impacts? First, several biofuels can be produced from waste, such as biodiesel from yellow grease. Cellulosic ethanol can also be produced from agricultural waste and wood products; however, this technology is not yet commercially available. These will result in much lower land impacts. It should be stressed that impacts to natural systems depend on biofuel type and the region from which it is derived. This applies not only to biogeography and ecological impacts, but also the quality of land. Peskett et al. (2007) indicate there are large tracts of land Africa, Southeast Asia, the Indian subcontinent and Latin and Central America that are degraded. These lands are not currently used for any productive purpose or were formerly used for cattle grazing. A wiser policy may focus on developing biofuels on agriculturally degraded land. Low input, high diversity grassland biomass has been identified as a biofuel that can be harvested on such land and still provide a reasonable yield (Tilman et al. 2006).

\section{CONCLUSION}

The aim of this paper was not to argue that all biofuels are environmentally destructive and unethical, but rather to discuss risks that may arise if ethical implications of policy are not considered. Energy systems that attenuate climate change may have other significant impacts that are not immediately apparent, such as land use. Policy makers should seek to understand potential impacts of new energy systems and the related ethical implications. Society should be informed of the trade-offs we face; if not, the policy may result in impacts that are not aligned with societal values and justice. Human values should ultimately guide policies, but trade-offs in impacts should be understood. This is why scientific fact ought to be coupled with normative theory in order to determine the best judgments for climate change policy.
Acknowledgements. Many thanks to Dr. David Keith for his advice on the ethical trade-offs created through biofuel systems, to Dr. Heather L. Maclean for direction on biofuels and greenhouse gas emissions, to Dr. Joule Bergerson for discussing preliminary ideas on the topic, to Juan Moreno-Cruz for comments on rural and urban economics, and to Alex Charpentier for his comments on biofuels.

\section{LITERATURE CITED}

Berndes G, Hoogwijk M, van den Broek R (2003) The contribution of biomass in the future global energy supply: a review of 17 studies. Biomass Bioenergy 25:1-28

Braun JV (2007) Biofuels and the poor: finding the win-wins. International Conference on Biofuels, July 5-6 2007. European Commission, Brussels. Available online at: ec.europa.eu/external_relations/energy/biofuels/sessions/ s4_05_von_braun_biofuels_poor_brussels_5-7-07.pdf

Buckland H (2005) The oil for ape scandal: How palm oil is threatening orang-utan survival. Friends of the Earth UK. Available online at: www.foe.co.uk/resource/reports/ oil_for_ape_summary.pdf

Chow J, Kopp R, Portney PR (2003) Energy resources and global development. Science 302:1528-1531

Daniels N (1979) Wide reflective equilibrium and theory acceptance in ethics. J Philos 76:256-282

Farrell AE, Plevin RJ, Turner BT, Jones AD, O'Hare M, Kammen DM (2006) Ethanol can contribute to energy and environmental goals. Science 311:506-508

Forge F (2007) Biofuels - an energy, environmental or agricultural policy? Library of Parliament, Science and Technology Division, Government of Canada. Available at: www.parl.gc.ca/information/library/PRBpubs/prb0637-e. htm\#why

Fulton L (2004) Biofuels for transport: an international perspective. International Energy Agency, Paris. Available online at: www.iea.org/textbase/nppdf/free/2004/ biofuels2004.pdf

Giampietro M, Ulgiati S, Pimentel D (1997) Feasibility of large-scale biofuel production. Bioscience 47:587-600

Harper T, Stein S (2006) Dialogical planning in a fragmented society: critically liberal, pragmatic, and incremental. Center for Urban Policy Research Press, New Brunswick, NJ

Harris R (2007) Fuelling controversy. Curr Biol 17:R107-R108

Hendrickson C, Lave L, Mathews HS (2006) Environmental life cycle assessment of goods and services: an input-output approach. Resources for the Future Press, Washington, $\mathrm{DC}$

Howe E (1990) Normative ethics in planning. J Plann Lit $5: 123-150$

Maclean HL (2006) Understanding energy markets II: future reserves, production, and prices for alternative energy sources. UCLA Conference on Global Energy and Climate Change, Lake Arrowhead, CA, October 22-24, 2006. Available online at: www.uclaextension.edu/arrowhead/ links.cfm

Mathews JA (2007) Biofuels: what a biopact between north and south could achieve. Energy Policy 35:3550-3570

Narasimhan TN (2007) Limitations of science and adapting to nature. Environ Res Lett 2:1-5. Available online at: www.iop.org/EJ/toc/1748-9326/2/3

Nielsen K (1996) Naturalism without foundations. Prometheus Books, New York

Pennsylvania Consortium for Interdisciplinary Environmental Policy (2004) The Buenos Aires draft declaration on the 
ethical dimensions of climate change. Available online at: http://rockethics.psu.edu/climate/declaration.pdf

Peskett L, Slater R, Stevens C, Dufey A (2007) Biofuels, agriculture and poverty reduction. Final technical output for the UK Department for International Development. Overseas Development Institute, London

Pimm SL, Raven P (2000) Biodiversity: extinction by numbers. Nature 403:843-845

Rawls J (2001) Justice as fairness: a restatement. Harvard University Press, Cambridge, MA

Runge CF, Senauer B (2007) How biofuels could starve the poor. Foreign Aff 6(3):41-53. Available online at: www.foreignaffairs.org/20070501faessay86305-p0/c-fordrunge-benjamin-senauer/how-biofuels-could-starve-thepoor.html

Stein S, Harper T (2005) Rawls' 'Justice as Fairness': a moral basis for contemporary planning theory. Planning Theory $4: 147-172$

Thomas CD, Cameron A, Green RE (2004) Extinction risk from climate change. Nature 427:145-148

Tilman D, Hill J, Lehman C (2006) High-diversity grassland biomass carbon-negative biofuels from low-input. Science 314:1598-1600

Editorial responsibility: Penny Kuhn (Managing Editor), Oldendorf/Luhe, Germany
Ugarte D, English B, Jensen K, Hellwinckel C, Menard J, Wilson B (2006) Energy resources and global development: economic and agricultural impacts of ethanol and biodiesel expansion study. Available online at: www.ethanol-gec.org/information/Ethanolagimpacts.pdf

United Nations Environmental Programme (UNEP) (2007) Transport. Division of Technology, Industry and Economics. Available online at: www.uneptie.org/energy/Act/ tp/index.htm.

Victor DG, Ausubel JH (2000) Restoring the forests. Foreign Aff 79:127-144

Vitousek PM, Mooney HA, Lubchenco J, Melillo JM (1997) Human domination of earth's ecosystems. Science 277:494-499

Worldwatch Institute (2006) Biofuels for transportation: global potential and implications for sustainable agriculture and energy in the 21st century. Prepared for the German Ministry of Food, Agriculture and Consumer Protection (BMELV) in coordination with the German Agency for Technical Cooperation (GTZ) and the German Agency of Renewable Resources (FNR). Earthscan, Washington, DC. Also available at: http://shop. earthscan.co.uk/ProductDetails/mcs/productID/753

Submitted: September 3, 2007; Accepted: November 12, 2007 Proofs received from author(s): December 5, 2007 